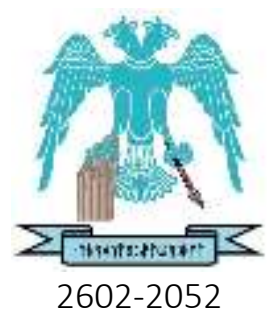

JOURNAL OF ENERGY SYSTEMS

VOLUME 2, ISSUE 4

DOI: $10.30521 /$ jes.454146

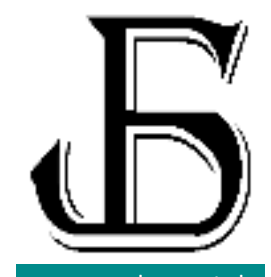

\title{
CFD modeling and multi-objective optimization of the axial fan parameters
}

\author{
Hasan Koten \\ Istanbul Medeniyet University, Istanbul, Turkey, hasan.koten@ medeniyet.edu.tr \\ ORCID: 0000-0002-1907-9420 \\ Arrived: 16.08.2018 Accepted: 23.09.2018 Published: 31.12.2018
}

\begin{abstract}
Axial fans are widely used in many areas to provide necessary air and heat and mass transfer, especially in HVAC industry. These fans are designed according to their cooling, heating and drying needs. In this optimization study, the performance of the 16-blade novel design axial fan CVS-AJ-R 1000 is analyzed in 3D using Computational Fluid Dynamics (CFD) technique. First, forward skewed 3D CAD geometry of axial fan is drawn and normalized for CFD pre-processing step. Then volumetric flow rates, pressures, energy consumptions and air velocities are evaluated in inlet and outlet region optimizing blade angle, shroud angle and other design parameters. Results are agreed with experimental studies. Optimized results are discussed and reported comparing with literature studies. As a results, the static pressure in the best-case decreases from 87.79 Pa to $54.59 \mathrm{~Pa}$, the flow rate increases from $1.3 \mathrm{~m} 3 / \mathrm{sec}$ to $2.78 \mathrm{~m} 3 / \mathrm{sec}$ at $1550 \mathrm{rpm}$.
\end{abstract}

Keywords: Axial fan, HVAC, Optimization, Energy.

Cite this paper as:

Koten H, CFD modeling and multi-objective optimization of the axial fan parameters. Journal of Energy Systems 2018; 2(4): 137-144, DOI: 10.30521/jes.454146

(C) 2018 Published by peer-reviewed open access scientific journal, JES at DergiPark (www.dergipark.gov.tr/jes) 


\section{INTRODUCTION}

Generally, fans as a mechanical device provide motion of air, vapor and different gases in a given system at the desired velocity [1-8]. To do this, it is utilized from difference across the fan rotor shown in Fig. 1. The axial fans are mostly used for the required gas flow for transfer operations in many industrial processes. As applications, HVAC systems, humidifiers processes, heat exchangers, mining ventilation systems, cooling electric equipment, exhausting systems, in steam boilers, cooling of heavy-duty vehicle engines can be evaluated. Axial fans can be considered as propeller fan, tube type axial fan and vane type axial fans. They generate high pressures makes them proper for difficult operating conditions, in high working conditions [9-11].

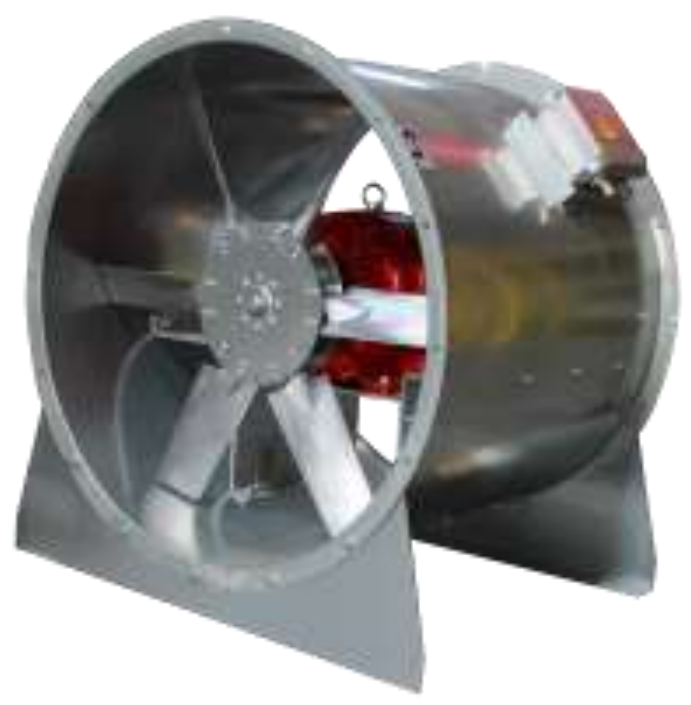

Figure 1. Axial fan of produced by CVS Co.

In literature, many studies were done about performance characteristics of fans. During a fire, it may be desirable to reverse flow in order to provide an escape way or to isolate a fire [10]. Also, in colder areas, the gas flow may be reversed to prevent ice buildup. When reversing main special designed fans, the mine operator usually does not know about operating characteristics of flow and pressure to expect. Laboratory and field tests of vane axial main special designed fans were conducted to establish forward and reverse performance characteristics under controlled conditions and in typical mine installations [12-19]. All fans tested were between 81 and 96 in. $(2.1$ and $2.4 \mathrm{~m})$ in diameter. The vane axial fan is shown in Fig. 2. The data obtained suggest that reverse performance characteristics are dependent upon the blade angle and the hub to tip ratio [20]. The special fan performance curve is shown in Fig. 2 there is also evidence that reverse performance can be predicted for a family of blade angles for a given hub to tip ratio. Generally, fan quantity is $30-60 \%$ less in reverse than when operating in the normal forward mode, with the static pressure equal to the square of the volume percentage change [20]. 


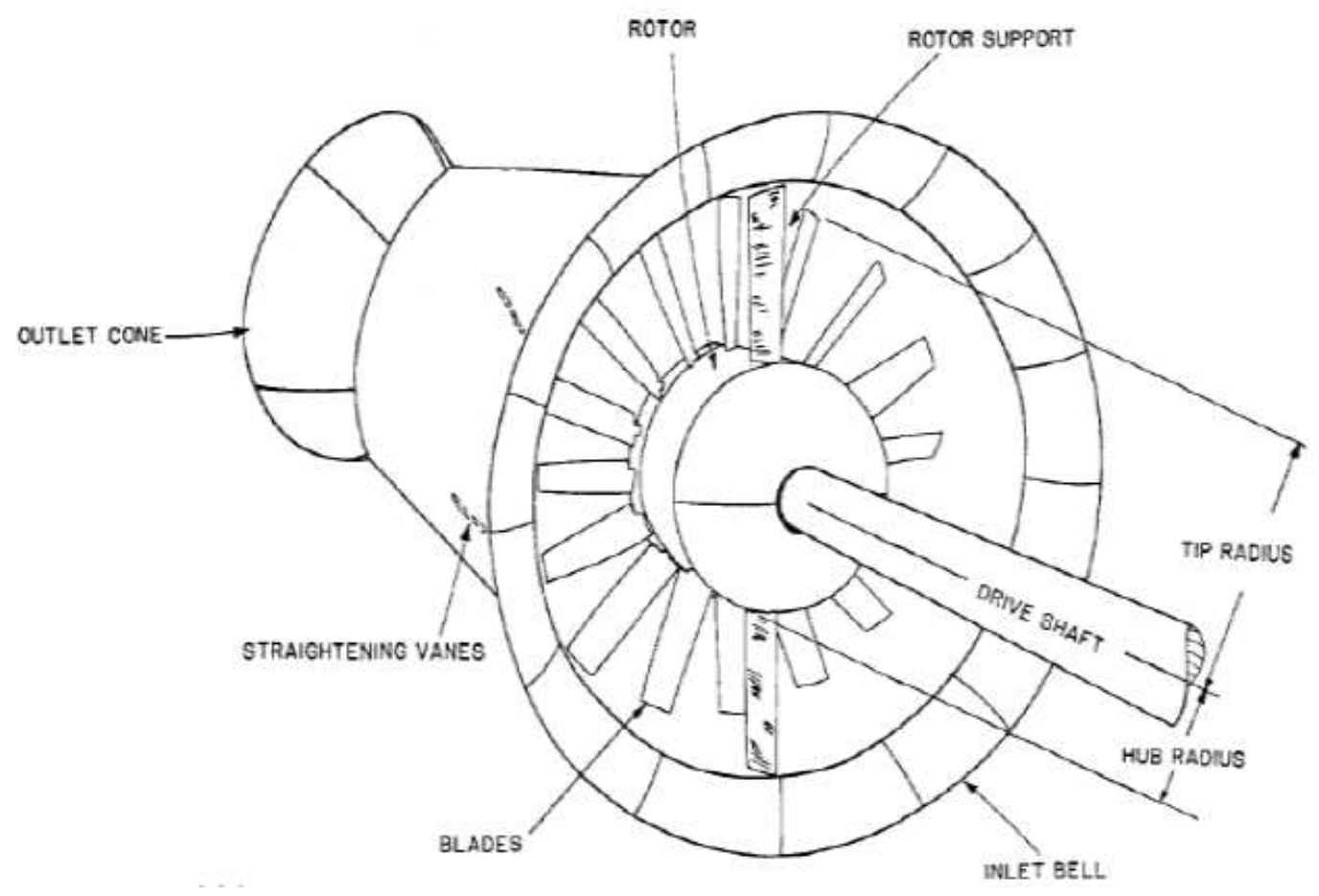

Figure 2. Vane axial Fan [10].

It is studied the flow mechanism analysis and experimental study of a forward-skewed impeller and a radial impeller in the low-pressure axial fan [20]. The forward-skewed blade was obtained by the optimization design of the radial blade and CFD technique. Measurement of the two blades was carried out in aerodynamic and aeroacoustics performance. Compared to the radial blade, the forward-skewed blade has demonstrated the improvements in efficiency. The aerodynamic curve is shown in Fig. 3.

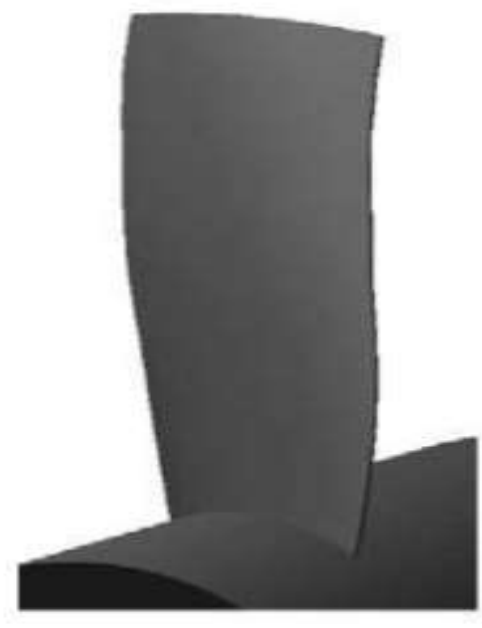

(a) Archetypal blade

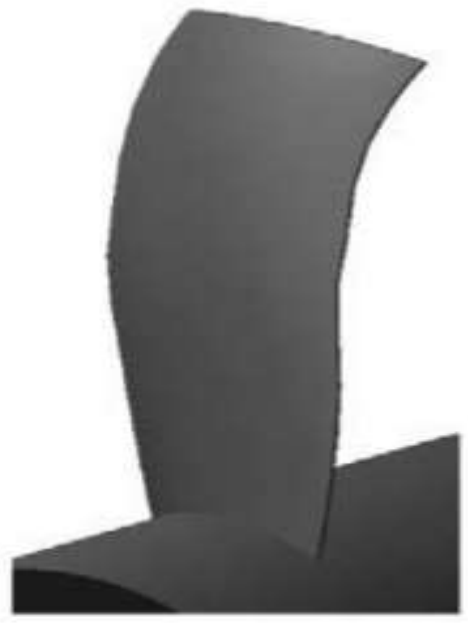

(b) Optimized blade

Figure 3. 3D models of archetypal blade and optimized blade [20].

Detailed flow measurement and computation were performed for outlet flow field for investigating the responsible flow mechanisms. The results show the forward-skewed blade can cause a span wise redistribution of flow toward the blade mid-span and reduce tip loading [21-32]. 


\section{CFD STUDY}

Solid geometry of axial fan, computational domain, boundary conditions, and numerical methods are prepared in CFD code to figure out the performance of axial flow fan. The geometry is created in CAD software and it is processed according to CFD methodology. The CAD geometry also is checked and repaired before the analyze. The analysis is carried out in the 3D CFD code. The CAD geometry of the axial fan and mesh structures were shown in Fig. 4. In the CFD calculation, commercial CFD code and multi-objective optimization code are used and RANS based study is applied in the analyze.

In this novel model, the axial fan designed at CVSair Co. is considered as base work. The setup consists of the axial fan having a diameter of $1000 \mathrm{~mm}$. The rotor consists of five blades, with a stagger angle of $27^{\circ}$. In the experimental study, generally, hot-wire anemometers are used to measure the speed of air. As an experimental study, in literature, the manometer is provided to measure the static pressure generated by the axial fan, Pitot tube is used to measure fluid flow velocity. The thermometer is provided to measure the temperature of incoming air; the barometer is provided to measure the atmospheric pressure. The electric motor is used as a power source for the axial fan, and then the streamline lattice used. The parameters studied with this system were flow rate, static pressure, velocity, pressure coefficient and flow coefficient [21].

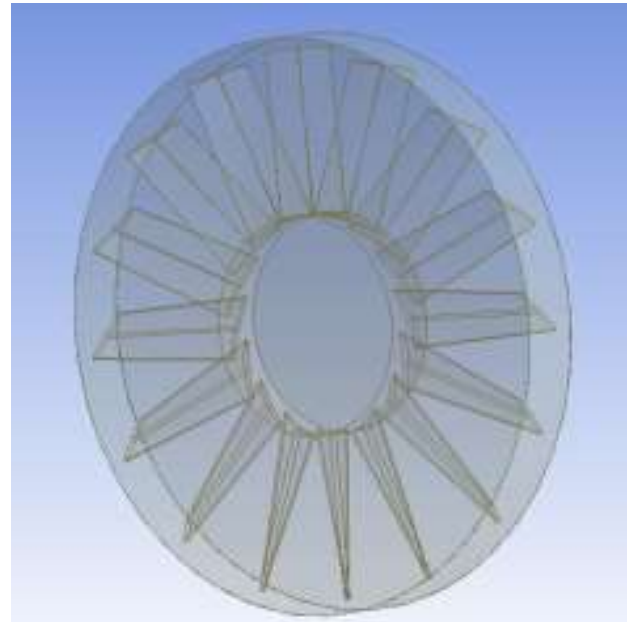

(a)

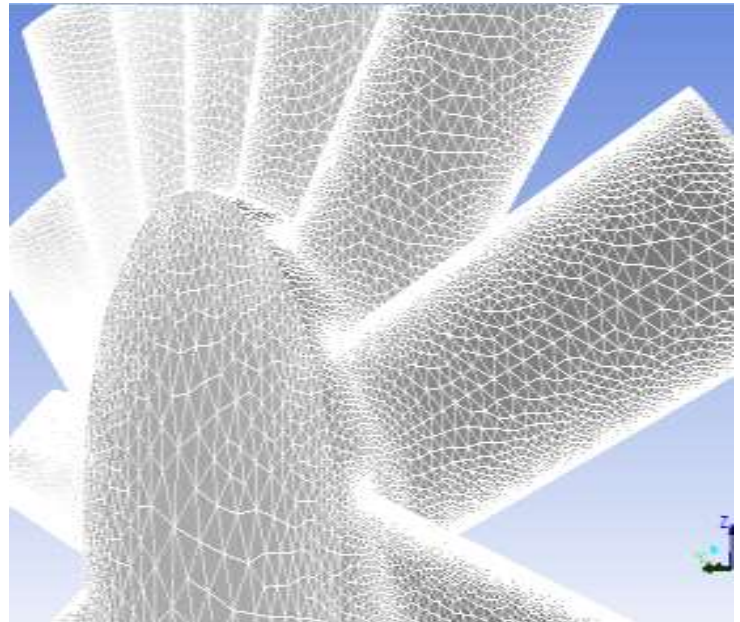

(b)

Figure 4. (a) CVS-AJ-R 1000 rotor shape and (b) mesh structure.

\section{RESULTS AND DISCUSSION}

In this optimization study, mesh geometry, the variation of temperature and velocity along the axial fan and along the slope of the case, and different values were investigated. Figure 4(a,b) shows the mesh geometry of the examined fan. Tetrahedral elements were used as a mesh element. Since cases examined during the study, the mesh sizes of the models were approximately between 800000 and 2000000 . Before the optimization study, the mesh dependency was analyzed and different cases were tried to get more reliable mesh structure. Boundary conditions were defined in commercial CFD code. At the exit of the fan pressure, outlet boundary condition was assumed with a static pressure due to the wind velocity over the fan exit. At the fan sidewalls, constant temperature and no-slip boundary conditions were assumed. Housing material was defined as steel. At the air inlet, standard atmospheric conditions were defined as the boundary condition. 
Table 1. Used cases in optimization study.

\begin{tabular}{lrrc}
\hline $\begin{array}{c}\text { Name } \\
\text { Units }\end{array}$ & $\begin{array}{r}\text { P17 flow rate } \\
\mathrm{m}^{3} / \mathrm{s}\end{array}$ & $\begin{array}{r}\text { P7 - Pressure inlet } \\
\text { Pa }\end{array}$ & $\begin{array}{c}\text { P9 - Energy } \\
\mathrm{J}\end{array}$ \\
\hline DP 0 (Base) & 1,56 & $-72,6336$ & $-165,938$ \\
DP 1 & 2,23 & $-72,1907$ & $-166,474$ \\
DP 2 & 2,26 & $-72,6749$ & $-168,178$ \\
DP 3 & 2,67 & $-80,0479$ & $-156,914$ \\
DP 5 & 3,34 & $-78,8074$ & $-149,285$ \\
DP 6 & 3,56 & $-65,101$ & $-186,154$ \\
DP 7 & 3,78 & $-82,9685$ & $-138,948$ \\
DP 8 & 4,32 & $-56,9191$ & $-203,982$ \\
DP 9 & 4,34 & $-63,1881$ & $-178,719$ \\
DP 10 & 4,45 & $-82,339$ & $-151,564$ \\
DP 11 & 4,56 & $-78,031$ & $-113,014$ \\
DP 12 & 4,78 & $-72,6336$ & $-165,938$ \\
DP 13 & 5,97 & $-72,6336$ & $-165,938$ \\
DP 14 & 9,87 & $-72,6336$ & $-165,938$ \\
DP 15 & 15,78 & $-72,6336$ & $-165,938$ \\
DP 16 & 18,99 & $-72,6336$ & $-165,938$ \\
DP 17 & 23,54 & $-72,6336$ & $-165,938$ \\
DP 18 & 27,85 & $-72,6336$ & $-165,938$ \\
\hline
\end{tabular}

Fig. 5 shows the velocity magnitudes along the axial fan from front and side zoomed view. The velocity vectors were distributed along the fan which was located at the center. In Fig. 6, streamlines were illustrated in duct.

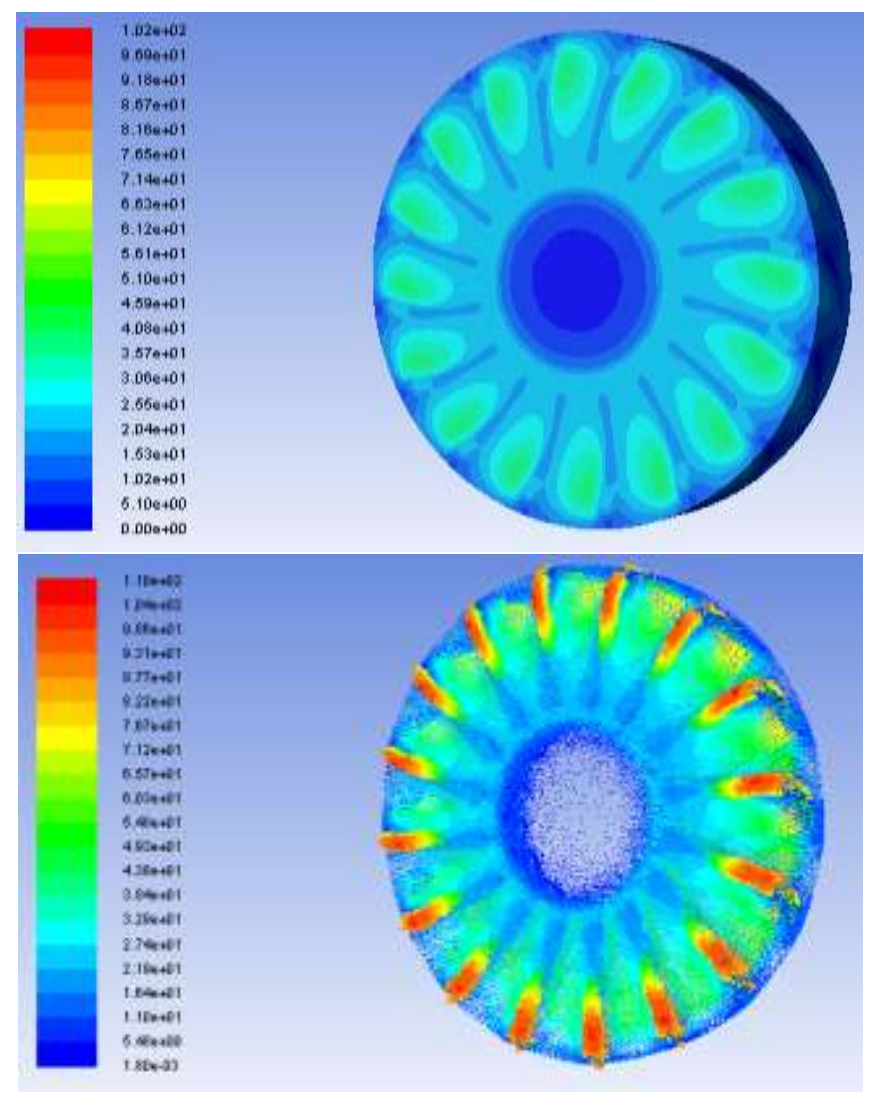

Figure 5: Velocity contours and vectors on blades full view.

After examining these results, investigation of the axial fan has been performed. Results were discussed on selected 19 cases. Volumetric flow rate, rotor diameter, blade height and housing height were 
changed parametrically to get optimum axial fan geometry. These results were discussed in axial fan characteristics.

In the multi-objective optimization study, novel design 16 bladed axial fan design points were investigated for blade angles, shroud angles and pressure inlet values as shown in Figs. 7 and 8. Thanks to the CFD model, several results were evaluated, such as air flow, volumetric flow rates and velocities on the blades. Selected 19 cases were examined and evaluated using CFD code via parallel processing. The volumetric flow rate is analyzed taking into consideration housing height, and fan diameter. This study has shown that the CFD code provides ease for the prediction of airflow in fan cases.

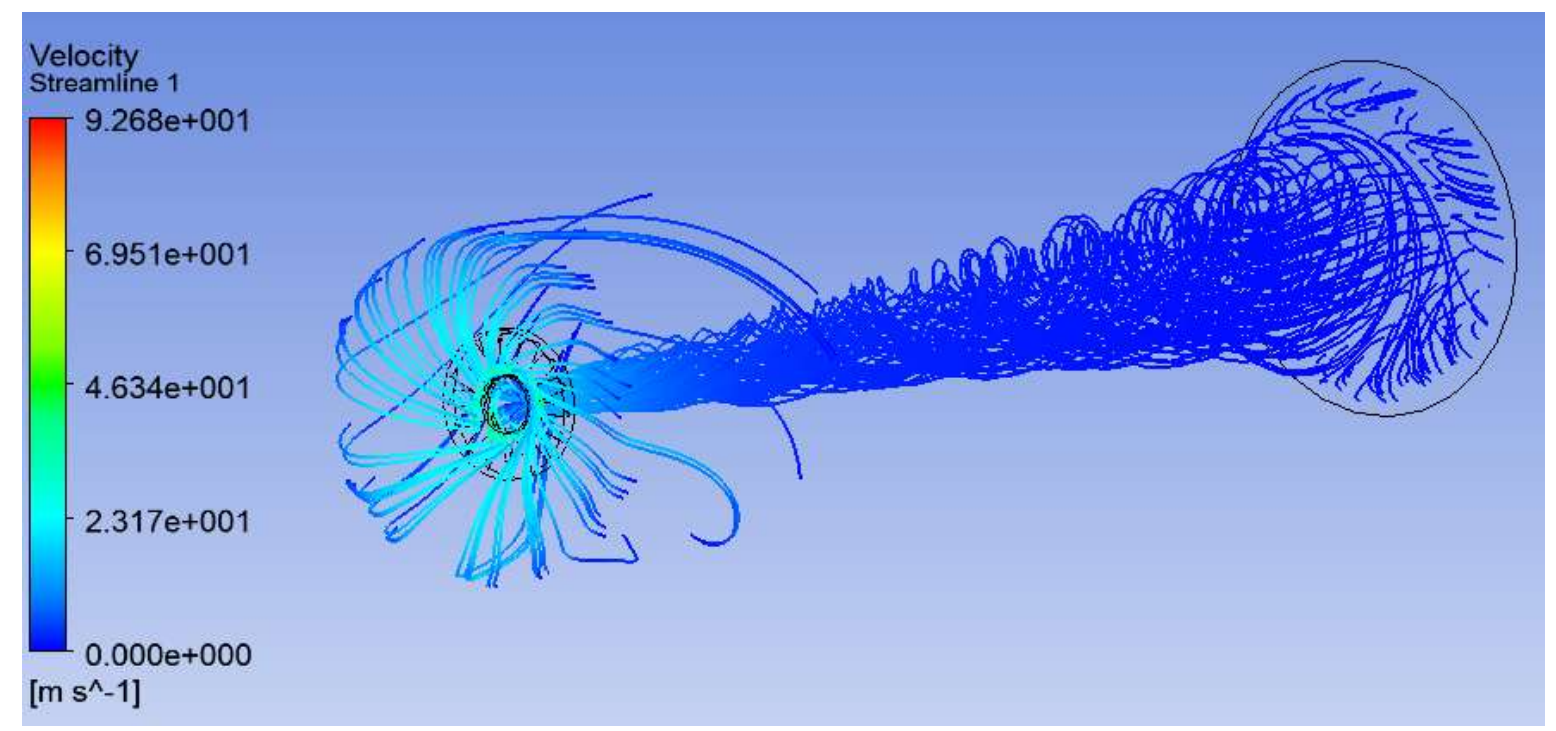

Figure 6: Stream lines around the fan blades, full and zoom view.

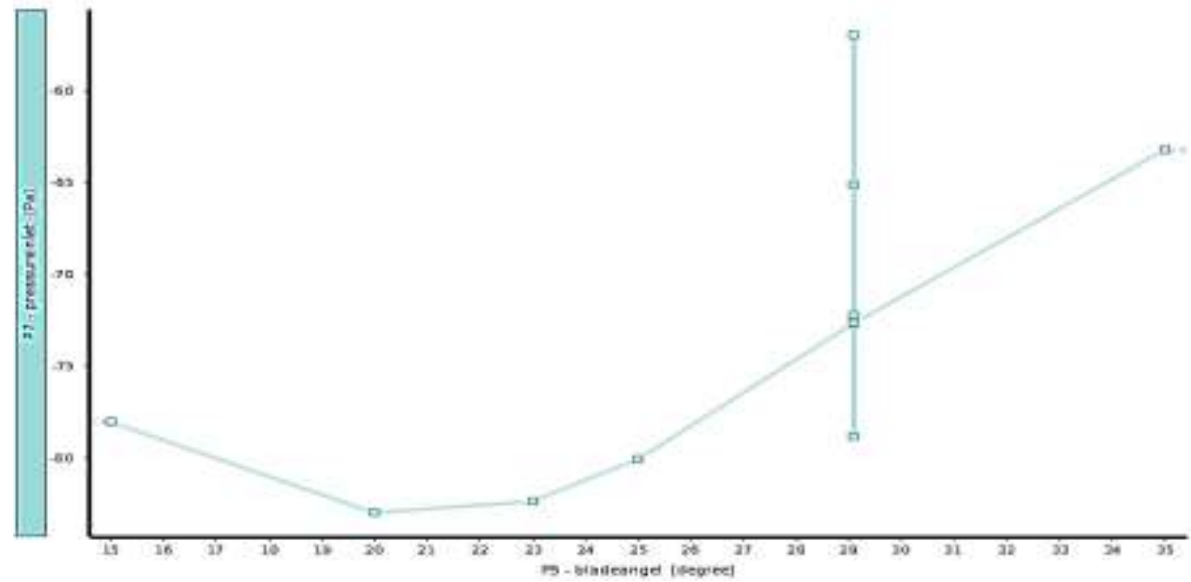

Figure 7: Design points in pressure inlets versus blade angles. 


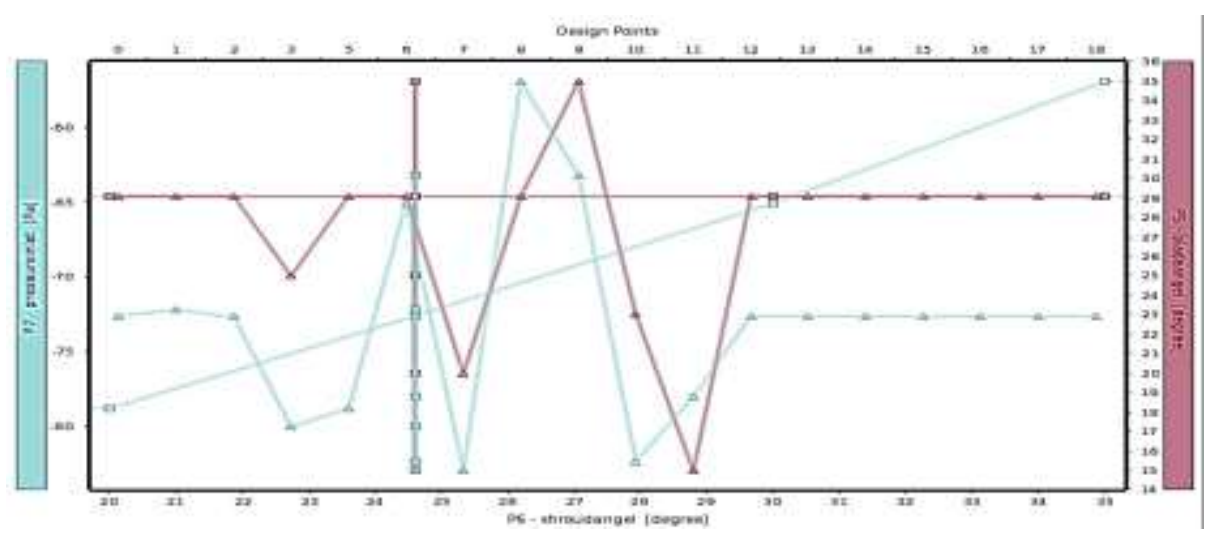

Figure 8: Optimization chart about blade angle, pressure inlet and shroud angle.

\section{CONCLUSION}

In the first part of the study, by using the CFD model, several results were evaluated, such as air flow, volumetric flow rates and velocities on the blades. Selected cases were examined and evaluated using CFD code via parallel processing. The mass flow rate is analyzed taking into consideration housing height, and fan diameter. This study has shown that the CFD code provides ease for the prediction of airflow in fan cases. To evaluate the effect of height and diameter on the ventilation flow rate, several dimensions were simulated. To evaluate the effect of height and diameter on the ventilation flow rate, several dimensions were also simulated.

Average volumetric flow rates for an axial fan, for different values, were showed in the result section. The pressure difference between fan back and forward side were evaluated. The magnitude in airflow rate difference increases alongside the fan. Also in this study, in axial flow fan within a multidimensional framework blade profiles computationally were modeled using k-e turbulence model. Different cases were investigated to get the proper boundary conditions using 3D CFD and multi-objective optimization code. As shown in Table 1, flow rates are changing between $1,56 \mathrm{~m}^{3} / \mathrm{s}$ and $27,85 \mathrm{~m}^{3} / \mathrm{s}$. The axial fan performance is analyzed at $1550 \mathrm{rpm}$, the studied parameters are the flow rate, static pressure, flow coefficient and pressure coefficient. The static pressure in the best case decreases from $87.79 \mathrm{~Pa}$ to 54.59 $\mathrm{Pa}$, the flow rate increases from $1.3 \mathrm{~m} 3 / \mathrm{sec}$ to $2.78 \mathrm{~m} 3 / \mathrm{sec}$ at $1550 \mathrm{rpm}$.

\section{Acknowledgements}

This work was supported by CVS air Co. and Istanbul Medeniyet University. The authors thank to Muharrem Ozturk, CVS air Co. and Istanbul Medeniyet University for their support.

\section{REFERENCES}

[1] Amano R.S, Lee.E.K, Xu c, Xie J. Investigation of Unsteady Flow Generated by an Axial Fan: Experimental Testing and Simulations. International Journal of Rotating Machinery. 2003; 3, 256-263.

[2] Bleier FP. Fan Handbook Selection Application and Design, McGraw Hill Publications, 1997.

[3] Bredell J.R, Kroger D.G, Thiart G.D. Numerical investigation of Fan Performance in a Forced Draft AirCooled Steam Condenser. J Applied Thermal Engineering. 2005; 26, 846-852.

[4] Bureau of Indian Standards, Centrifugal Fans, Standard No. IS-4894-1987, 1988.

[5] Bureau of Indian Standards, Propeller Type Ac Ventilation Fans, Standard No. IS-2312-1967, 1967. 
[6] Bureau of Indian Standards, Electric Pedestal Type Fans and Regulations, Standard No. IS-1169-1967, 1968.

[7] Bureau of Indian Standards, Electric Ceiling Type Fans and Regulations, Standard No. IS-174-1979, 1980.

[8] Culham, R. G. Fans Reference Guide, 4th Edition, Ontario Power Generation, Canada, 2001.

[9] Downie R. J, Thompson M. C, R, Wallis R. A. An Engineering Approach to Blade Design for Low to Medium Pressure Rise - Only Axial Flow Fans, J. Experimental Thermal and Fluid Science, 1993; 6, 376- 401.

[10] Dunn M. F, Kendorski F. S, Bhattacharya S, Rajaram V. Reverse Performance Characteristics of Main Mine Fans. 1983; 1, 59-68.

[11] Estevadeordal J, Gogineni S, Copenhaver W, Bloch G, Brendel M. Flow Field in a Low-Speed Axial Fan: A DPIV Investigation, J. Experimental Thermal and Fluid Science, 2000; 23, 11-21.

[12] Jang C M, Sato D, Fukano T. Experimental Analysis on Tip Leakage and Wake Flow in Axial Flow Fan According to the Flow Rates, J. Fluids Engineering, 2005; 127, 322-329.

[13] Kergourlay Gerald, KouidriSmaine, Rankin Gary W, Rey R. Experimental Investigation of 3D Unsteady Flow Field Downstream of Axial Fans. J. Flow Measurement and Instrumentation. 2006; 17, 303-314.

[14] Kokturk T. Design and Performance Analysis of Reversible Axial Flow Fan. M.Sc. Department of Mechanical Engineering, Middle East Technical University, Turkey, 2005.

[15] Kroger D.G. Fan Performance in Air -Cooled Steam Condenser. 1993; 14, 391-399.

[16] Kwon E-Y. Beak K-W, Chow N-H, Kim, H-K, Jung I-J. Some aerodynamic Aspects of Centrifugal Fan Characteristics of an Automotive HAVC Blower, SAE Technical Paper Series. 2001; 1, 283-291.

[17] Lin S.Huang C. An Integrated Experimental and Numerical Study of Forward-Curved Centrifugal Fan. J. Experimental Thermal and Fluid Science. 2001; 26, 421-434.

[18] Morris SC, Good JJ, and Foss JF. Velocity Measurements in the Wake of an Automotive Cooling Fan, J. Exp. Thermal Fluid Science. 1998; 17, 100-106.

[19] Oro J M F, Díaz K M A, Morros C S, Marigorta E B. Unsteady Flow and Wake Transport in a Low-Speed Axial Fan with Inlet Guide Vanes, J. Fluids Engineering. 2007; 129, 1015-1029.

[20] Yang CX, Ai Q, Zhou J. Design and numerical simulation of small axial fan. J Electron Dev. 2007; 30(5), 1846-1851.

[21] Peng S. The Kinematic Analysis of 3-D Swept Shock Surfaces in Axial Flow Compressors, J. Turbomacinery. 2001; 123, 490-500.

[22] Ramtekkar R. Performance of NACA and JOUKOWSKI Bladed Axial Flow Fans With Variable Inlet Guide Vanes. MSc, Department of Mechanical Engineering, IIT Guwahati India, 2008.

[23] Ravindranath, V., and Lakshminarayana, B. Mean velocity and Decay Characteristics of the Near and FarWake of a Compressor Rotor Blade of Moderate Loading, J. Engineering Power. 1980; 102, 535-548.

[24] Reynolds, B., and Lakshminarayana, B. Blade Loading and Span Wise Effects on Wake Characteristics of Compressor Rotor Blades, J. Aircraft. 1980; 19, 97-103.

[25] Roy B, Chouhan M, Sivadas P. M. Aerodynamics Studies on Swept Blades for Axial Flow Fan/Compressor, IEI Journals. 2005; 85, 47- 53.

[26] Schmidt K, and Patterson DJ. Performance Results for a High Efficiency Tropical Ceiling Fan and Comparison with Conventional Fans-Demand Side Management via Small Appliance Efficiency, Renewable Energy. 2001; 22, 169-176.

[27] Sears WR. Some Aspects of Non-Stationary Airfoil Theory and its Practical Application. J. Aeronautical Science, 1941; 8, 104-108.

[28] Singh K. Development of a Test Facility to Study the Aerodynamic Performance of Axial Flow Fans, MSc, Department of Mechanical Engineering, IIT Guwahati, India, 2005.

[29] Tsai B.J, Wu C.L. Investigation of a Miniature Centrifugal fan. J. Applied Thermal Engineering. 2006; 27 , 229-239.

[30] Votari N. Aerodynamic Performance of Axial Flow Fans with NACA and Joukowski Blade Profiles, MSc, Department of Mechanical Engineering, IIT Guwahati, India, 2007.

[31] Wallis R. A. Axial Flow Fans and Ducts, John-Wiley Publication, Canada, 1983.

[32] Wilcox D.C. Turbulence Modeling for CFD. DWC Industries, Inc. La Canada, California, 1994. 